\title{
Progress of Fundamental Fire Research in China
}

\author{
WEICHENG FAN ${ }^{1,2}$, NAIAN LIU ${ }^{1}$, and HAIXIANG CHEN ${ }^{1}$ \\ ${ }^{1}$ State Key Laboratory of Fire Science \\ University of Science and Technology of China \\ Hefei, Anhui 230026, P. R. China \\ ${ }^{2}$ Center for Public Safety Research \\ Tsinghua University \\ Beijing 100084
}

\begin{abstract}
A fire-year research project "Fire Dynamics and Fundamentals of Fire Protection" (20022007) has been sponsored by the China NKBRSF (National Key Basic Research Special Funds), in order to gain deep understandings of natural fire phenomena and whereby facilitate the development of practical fire safety design/engineering, management and firefighting technologies. The project has been carried out for more than two years since 2002, with successful establishment of a multidisciplinary collaboration network of most famous China universities and institutions in the field of fundamental fire research. This review summarizes the new significant progress of the project during 2002-2004. A prospect of fundamental fire research in China is also presented.
\end{abstract}

KEYWORDS: China, fundamental fire research, fire dynamic theory, fire protection technology

\section{INTRODUCTION}

In the past few years, along with the economy booming fast and the increasing fuel demands of industries, the fire safety situation in China has been considerably severe, and fire safety problems have been a major concern for Chinese public and government. In 2002, the project Fire Dynamics and Fundamentals of Fire Protection was promoted by fire safety scientists and sponsored by the China NKBRSF (National Key Basic Research Special Funds, briefly named as 973 program), in order to gain deep understandings of natural fire phenomena and whereby facilitate the development of fire protection technologies. The project addresses fire safety knowledge innovation by transdisciplinary cooperation, and most famous research universities and institutions in the field of fundamental fire research in China have been organized to work together for the project. This review is an attempt to present the new significant research developments of this project that occurred in the years 2002-2004.

\section{OUTLINE OF THE PROJECT}

As the title states, the project focuses on both the dynamical evolution theory of fire phenomena and fundamental principles of fire safety technologies. The major points include six research topics as follows:

1) Fire Formation and its Propagation

2) Generation and Release of Fire Smoke and Its Toxicity

3) Fire Risk Assessment and Performance-based Design based on Fire Dynamics and Statistical Theory

4) High Quality Fire Retardant Materials 
5) Intelligent and Reliable Recognition of Fire Signals for Detection Technology

6) Clean Fire Suppression Technology with High Efficiency

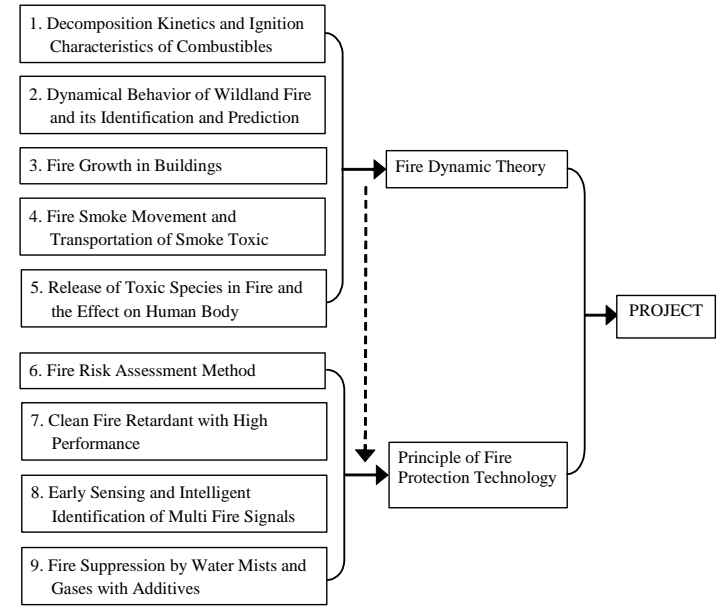

Fig. 1. Framework of the sub-projects of the PROJECT fire dynamics and fundamentals of fire protection.

The project divides the above six topics into 9 sub-projects (see Fig. 1). The first five sub-projects aim at gaining deep insight into the complex fire dynamical behaviors by experimental or simulation means, so as to reveal the twofold (deterministic and statistical) features of fire. The other four sub-projects address the principles of advanced fire protection technologies.

The core universities and institutions include University of Science and Technology of China (USTC), Tsinghua University, Zhejiang University, The Hong Kong Polytechnic University, (TianJin, Sichuan, Shenyang and Shanghai) Fire Research Institutes of MPS, and Research Institute of Forest Ecology. More than ten other universities act as the partners of this project.

\section{FIRE FORMATION}

\section{Decomposition Kinetics of Solid Combustibles}

The thermal decomposition of solid materials is recognized as an important topic for the scientific description of fire formation, since in practice solid combustibles such as wood, textile, plastics and decoration boards are frequently implicated in fire incidence. The decomposition kinetics plays a basic role in modeling of the subsequent ignition and fire propagation processes.

The group of Liu [1-2] collected nearly 20 types of wood and leaf samples from Chinese different forest zones and successfully examined the mass loss kinetics of the thermal decomposition with linear temperature programming in air atmosphere. A simple kinetic description, named as First Order Pseudo Bi-component Separate-stage Model (PBSMO1), was developed as illustrated in Fig. 2. The model assumes that the mass loss process of any wood or leaf sample consists of three steps. The major point is after water evaporation, the subsequent two mass loss steps of two pseudo components decompose respectively at lower and higher separate temperature regions, rather than at the global 
temperature region as previously used by other authors. The kinetics of the two components abides by the first order model function.

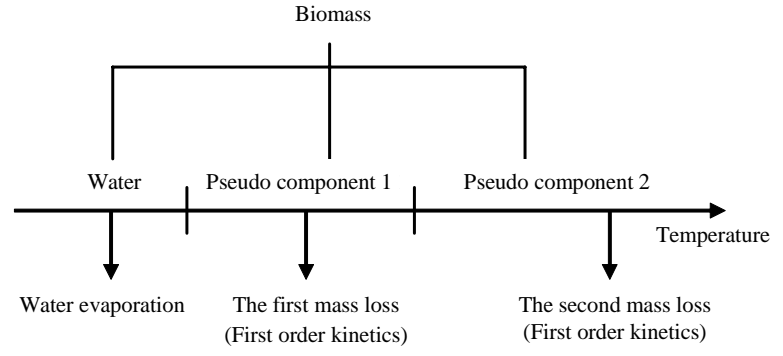

Fig. 2. Schematic illustration of the kinetic model PBSM-O1 for biomass decomposition in air atmosphere.

The PBSM-O1 model has been further testified and generalized to other building boards by other researchers [3-8]. For example, Shi et al. [6] investigated the decomposition behavior and kinetics for common wood materials used for building and decorating, and especially examined the effects of heating rate, particle size and initial weight on the decomposition kinetics. The results demonstrated the applicability of PBSM-O1 model. They further found that the decomposition of natural fiber, chemical fiber and the blending of them can be divided into several phases according to the peaks on the DTG curves [7], indicating that the separate stage model scheme is suitable for the kinetic description. They also simulated fire environments by changing the oxygen concentration with time in the thermobalance system and obtained the apparent kinetic parameters for the decomposition processes of biomass and textile [8]. These parameters are expected to be used in the modeling of smoldering and the fire early stage when heating rate is relatively low. Punnaruttanakun [9] even found the PBSM-O1 model shows a good fit with the experimental data of sludge decomposition.

The research of secondary reactions inside particle wood decomposition is greatly limited by the level of up-to-date measure technology. Yu et al. [10-11] presented a reasonable numerical simulation by a comprehensive mathematical model in which the kinetic submodel of secondary reactions of primary pyrolytic product is involved. The model also includes the processes of the yielding, consuming, accumulating or escaping of the major pyrolysis products in developing porous matrix of reacting wood.

In differential kinetic analysis for solid decomposition, the determination of the kinetic parameters is generally complicated by the presence of noises. Liu et al. [12-13] successfully developed a "Two-stage Gaussian Smoothing Strategy" for biomass decomposition data pre-treatment.

\section{Ignition Behavior and Criterion}

In physical sense, ignition and decomposition are highly correlated since for solid materials ignition is generally motivated by decomposition process under certain conditions. Yang et al. [14] investigated the effect of an external heat flux on the decomposition and combustion of charring materials using a cone calorimeter and a radiation platform, particularly with a small heat flux. They proposed a modified model of decomposition for charring materials, in which the heat loss by convection and radiation due to the surface temperature rising and also shrinkage of the chars external 
surface were considered. They found that the ignition time is linearly related to the conditions such as the radiation flux, the distance between the sample and the radiation source, and the sample obliquity [15]. They also studied the charring of wood under simulated fire [16], in which the effect of radiation flux, distance between the sample and heat source, and the radiation time on the charring rate was formulated. Scale effect on mass loss rate of some woods was investigated by experimental means [17].

The criterion to determine under what conditions ignition would occur is a research hotspot for fire formation. Literature generally assumes that ignition corresponds to a known, constant surface temperature $\mathrm{T}_{\mathrm{ig}}$, or critical pyrolysate mass flux. Comparatively, a combined criterion [18] was proposed to describe the ignition of wood under varying radiant heating rate, that is (1) surface temperature reaches $500^{\circ} \mathrm{C}$, and (2) the varying rate of heat flux after charring is higher than $0.07 \mathrm{~kW} \cdot \mathrm{m}^{-2} \cdot \mathrm{s}^{-1}$. Another ignition criterion of wood was also proposed based on the cone calorimeter test results [19], by assuming that when the energy received by the material is higher than the ignition energy (determined from the cone calorimeter tests), the material will ignite.

\section{FIRE GROWTH}

Several groups of this project are devoted to the fire growth in buildings or outside (e.g. in wildland). General burning behavior of materials and fire propagation are certainly major points, and additionally, the special fire phenomena such as backdraft, flashover and fire whirl have been especially addressed.

\section{Burning Behavior of Materials}

Ji et al. [20] investigated the heat release rate, time to ignition, yield of $\mathrm{CO} / \mathrm{CO}_{2}$ and light extinction of wood, PVC and polyurethane at different external heat radiation level with a cone calorimeter. Based on the oxygen consumption theory, they proposed a heat release rate model and mass loss rate model, and further used these models including the ignition criterion in the zone modeling of fire [21]. The results showed that the complicated zone model of fire can be used to predict the fire development in a single compartment according to the species of combustibles, their quantities and distribution.

Song et al. [22] investigated the suppression method of adding sand into the fire source (gasoline). They found that by assuming a transition layer below the sand surface, the combustion process of the fire source can be simplified, and the time to the upper layer peak temperature, the peak temperature value and the rate of extinguishment have obvious dependence on the volume ratio of sand to the fire source (gasoline).

The cone calorimeter has been used widely for the research of material flammability [21,23-24]. Zhang et al. found that without appropriate corrections, the heat release rate measured by the cone calorimeter for the polymer composites containing large quantities of endothermic fillers would be overestimated [23-24]. They put forward a procedure for correction and realized a more accurate measurement.

\section{Backdraft}

Backdraft generally occurs in a limited-ventilation building and develops from fires of either ordinary combustibles or ignitable liquids that become oxygen starved yet continue to generate a fuel-rich environment. One group of the project developed a backdraft apparatus at SKLFS (Fig. 3), which consists of a reduced-scale compartment, fuel system, ignition system and data acquisition system. The compartment $(\mathrm{L} \times \mathrm{W} \times \mathrm{H}$ : 
$1.2 \mathrm{~m} \times 0.6 \mathrm{~m} \times 0.6 \mathrm{~m})$ was fitted with one opening $(\mathrm{W} \times \mathrm{H}: 0.2 \mathrm{~m} \times 0.6 \mathrm{~m}$ in the middle of the end wall). It was found that the key parameter determining the occurrence of backdraft is the mass fraction of unburned fuel (unburned methane in this study) [25-26]. When the mass fraction of unburned fuel exceeds a critical value, i.e., 9.8\%, backdraft will take place. The results also showed that the critical mass fraction values of total hydrocarbons determining the occurrence of backdraft vary with inlets of different geometries [26].

The mitigation of backdraft in compartment fires with water mist was also examined [2728], indicating that water mist is an effective means to suppress backdraft primarily by reducing unburned fuel mass fraction, rather than by a thermal mechanism of cooling.

As for the physical mechanism of backdraft, a simplified mathematical model has been established based an energy balance equation, which indicated that the backdraft phenomenon is in essence one kind of typical catastrophe behavior [29-30].

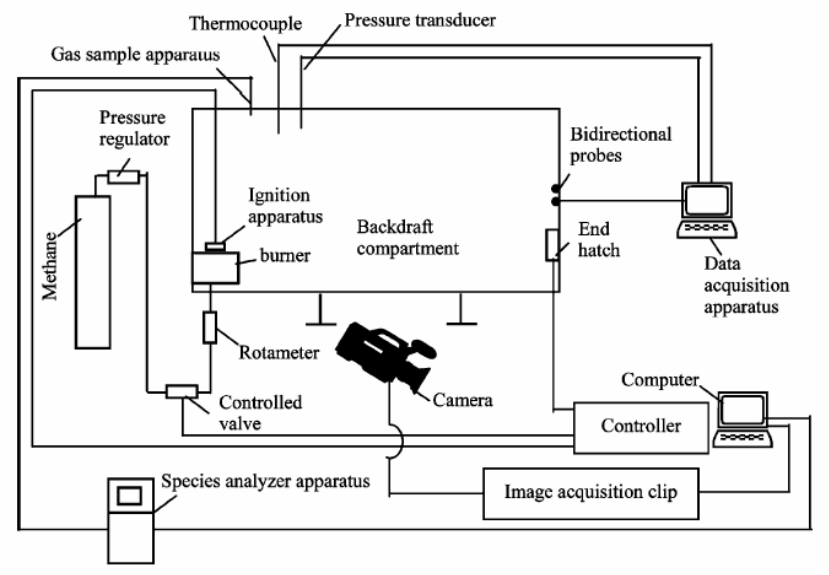

Fig. 3. Schematic of the backdraft experimental apparatus.

\section{Flashover}

Flashover in building fires is a suggestive of a catastrophe process. In the project, the catastrophe dynamics of flashover was investigated by mathematical method, whereby a model of flashover based on energy balance equation was established, and the corresponding relationship between system control variables and operating conditions was examined. Results indicated that flashover in building fires is in essence a phenomenon of swallowtail catastrophe [31]. A fuel mixture of chemistry fuel with oxidizing agent has been developed for re-appearing a fire flashover in a confined compartment [32]. The flashover temperature and smoke production could be controlled by adjusting the dispensation of fuel mixture. The Field-Zone-Network model proved to be feasible by analyzing the variable regularity of smoke parameters of fire flashover. The smoke production, movement, back flow and fall-in during flashover were analyzed.

\section{Fire Whirl}

Fire whirl is a rare but potentially catastrophic form of fire in wildland fire or large-scale city fire, in which the swirling buoyant fire plumes are known to significantly increase the danger of naturally occurring or post-disaster fires. Generally there must be an organized source of angular momentum to achieve large swirl velocities as air is entrained into the fire plume. 
Group of Wu developed a fire-wall firewhirl model (Fig. 4) [33], in which four bars of liquid fuels are used to produce the enclosure where firewhirl may be induced. This model scheme differs from that of Satoh and Yang [34] in that the latter used four solid channel walls to form the enclosure. Comparatively, the new model scheme has higher similarity with some practical situations especially in wildland fires. The model can also be used to investigate the interactions among different fire spots. Numerical results showed that the under certain conditions firewhirl can be induced. The temperature and velocity fields were extensively examined.

At the end of 2004, a large scale firewhirl apparatus was constructed at SKLFS, which is based on the model of Satoh and Yang, with four fireproof channel walls to form the enclosure. The height of the enclosure is $15 \mathrm{~m}$ (Fig. 5). The initial experiments realized a $9 \mathrm{~m}$ high firewhirl [35]. More extensive researches are still being conducted.

\section{FIRE MODELING}

The numerical fire modeling can provide a wealth of information concerning the fire growth and other dynamic aspects of fire, and also can be used to observe specific fire phenomena without the expense of full scale testing, to reconstruct specific fire scenarios or to design fire protection systems.

One group developed a multi-layer zone fire growth model to predict the vertical temperature distributions in a single room [36]. The fire room volume is divided into a number of horizontal layers (Fig. 6), in which the temperature and other physical properties were assumed to be uniform. The principal equations for each laminated horizontal layer were derived by the conservation equations of mass and energy. The implemented fire sub-models include models of combustion, fluid flow and heat transfer. The model may have high engineering value for its economy and accuracy of computation. Another new model named LFZN (LES-Field-Zone-Network model) was developed to simulate the fire smoke movement in a single fire room [37]. The model uses the Large Eddy Simulation (LES) technique to filter three-dimensional compressible Navier-Stokes equations at low Mach number, and shows better performance than ordinary FZN model and CFAST.

As for the numerical method of turbulence in fire simulation, one scheme combining RANS and DES (detached-eddy simulation) was proposed [38]. This scheme holds the accuracy of DES and the high computing efficiency of RANS.

Recently, smoke movement and ambient airflow in a typical two-storey confined stairwell under fire scenarios were studied numerically by LES [38-39], showing the existence of fairly distinct layers of hot smoke and ambient air under different fire scenarios. Heat release rate shows a remarkable effect on distributions of smoke temperature, velocity and oxygen concentration. The backdraft phenomenon was predicted in the simulation when the door was suddenly opened.

In engineering field, some practicable simulation methods have been developed to predict smoke movement [40] and smoke filling [38,41]. The engineering simulation methods have been applied in the design or fire risk assessment of large buildings.

In forest fire research, the numerical model [42] of fire spread regarding the influence of wind velocity and slopes was established and applied in the aided decision-making system for forest fire prevention. 


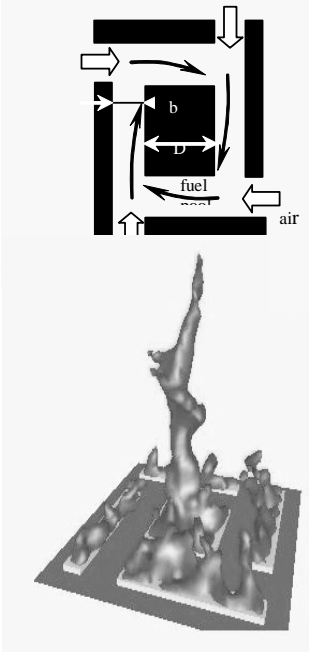

Fig. 4. Fire-wall firewhirl model.

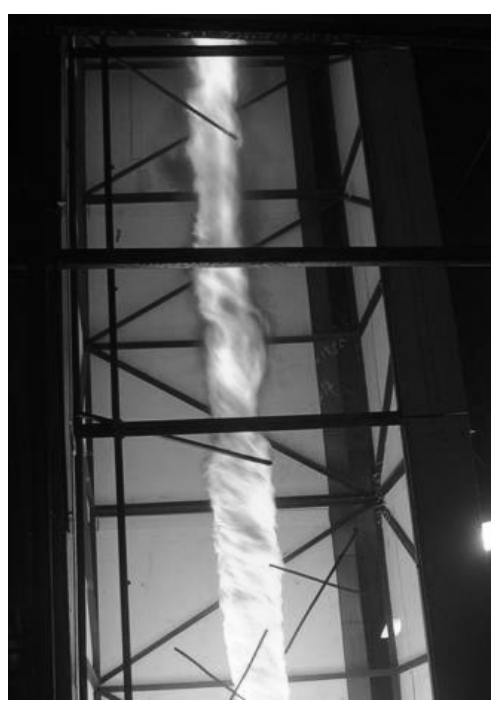

Fig. 5. Firewhirl experiment at SKLFS.

The enclosure: $15 \mathrm{~m}$ high; firewhirl: $9 \mathrm{~m}$ high.
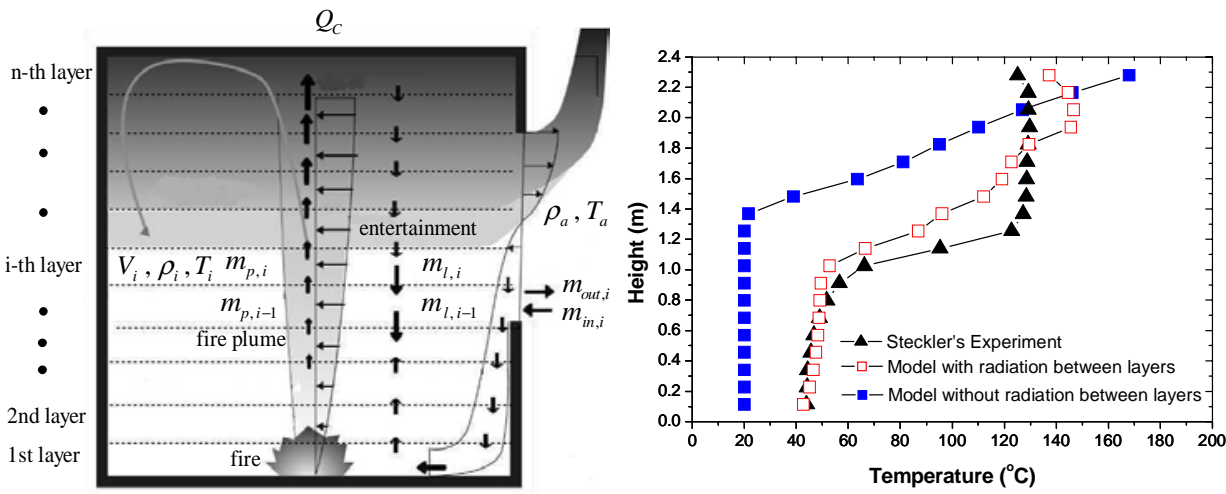

Fig. 6. Multi-layer zone fire growth model.

\section{FIRE STATISTICS}

Vegetation burning can produce some gases such as $\mathrm{CO}_{2}$ and $\mathrm{CH}_{4}$, which have significant effects on environment and climate in short or long term. Researchers of this project calculated the consumed biomass due to forest fires according to the statistics of forest fires in China from 1991 to 2000 [43]. The results showed that during the decade forest fires burned average 5-7Tg biomass each year and directly emitted carbon 20.2428.56Tg, $\mathrm{CO}_{2}$ 74.2-104.7Tg, $\mathrm{CH}_{4}$ 1.797-2.536Tg, smoke aerosols 0.999-1.410Tg. The average emission of carbon dioxide accounts for $2.7-3.9 \%$ of the total emission of China (using the data of 2000).

By analyzing the historical forest fires data (1980-1999) in Heilongjiang province, researchers also found forest fires have circles and frequency in time [44-45]. They 
studied the fluctuation of the centroids using spectrum analysis method and calculated the centroids of annual fire scars and annual fire points. Annual precipitation and annual mean temperature were found to have important impact on the fluctuation of centroids.

Song et al. [46-48] analyzed forest-fire data in China and other countries, and found Selforganized criticality (SOC) behavior characterized by the power-law relation of frequency-size distribution existing in the forest fires data (Fig. 7). The SOC characteristics are invariant with time and a broad range of forest size, and can be explained by the classical forest-fire model. The SOC characteristics have practical implications, and from which the forest-fire regimes in the next several decades can be forecast. The occurrence frequency of small and medium fires can be used to quantify the risk of large fires.

City fire data in China was also analyzed with similar procedures [49]. The frequencyloss distribution of large city fires satisfies a good power-law relationship. The results indicated that the power-law distributions of city fires are scale-invariant and timeinvariant.

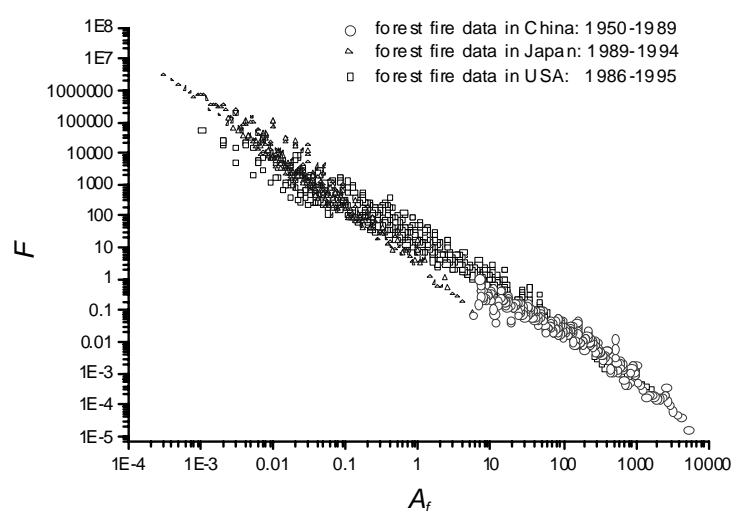

Fig. 7. SOC behavior of forest fire data: power-law relation of frequency-size distribution.

\section{FIRE RISK ASSESSMENT METHOD}

Advanced fire risk assessment method depends on accurate evaluations of both deterministic fire behavior and fire statistical characteristics. In fire emergency, safety evacuation is especially important in preventing great casualties from fire, smoke and toxic gases. Researchers [50-51] successfully developed a Combined Fire Evacuation (CFE) model by considering the human behavior during evacuation and integrating the effect of fire development and product. The model has been justified by applications in practical fire cases.

Song et al. [52] simulated the pedestrian evacuation during fire urgency by social force model. The influences of the width and thickness of the exit, as well as the expired speed, on evacuation were studied especially, and it was shown that the building structure has asymptotic effects on evacuation time, and there exists an optimal expired speed under which the pedestrians egress fastest. They further simulated the pedestrian evacuation dynamics in crossing exit by the lattice-gas model of biased random walkers without back step [53]. A series of critical boundary densities which indicate the jamming transition were obtained under different values of width of longitudinal route. 
Sun et al. [54] presented the probability distribution functions of fire load and the fire duration time of office buildings. They developed a method to evaluate the collapse probability of building caused by fire. Another work discusses the application of design fire and fire hazard degree analysis in hazard identification of performance based fire protection design [55].

During the past two years, the fire risk assessment methods developed in this project have been widely applied in some important building engineering projects, such as Beijing Main Stadium, Basketball Stadium, and Bicycle Stadium for the 2008 Olympic Games.

\section{FIRE RETARDANCY, DETECTION AND SUPPRESSION TECHNOLOGIES}

\section{Fire Retardant with High Efficiency}

One group successfully synthesized acicular, sheet, and rod-like $\mathrm{M}_{\mathrm{g}}(\mathrm{OH})_{2}$ nanocomposites [56-59], which has been put into practice with an annual production of 100 tons. Multiplex nanocomposites were also successfully synthesized by a chromatographer and intercalation method, which has high efficiency of fire retardancy [56,60-72]. Researchers also successfully synthesized the PE-g-MA/MgAl-LDH exfoliated nanocomposites [73-74]. The new nanocomposites show a fast charring process in the temperature range from 210 to $360^{\circ} \mathrm{C}$ and a higher thermal stability in the temperature range from 370 to $500^{\circ} \mathrm{C}$ than the pure $\mathrm{PE}-\mathrm{g}-\mathrm{MA}$. The rate of thermal oxidation of PE-g-MA chains in the nanocomposites is much slower than that in the pure PE-g-MA in the temperature range from 200 to $320^{\circ} \mathrm{C}$. This kind of exfoliation nanocomposite is promising for use in flame-retardant polymeric materials.

\section{Multi-signal Fire Detection}

In fire detection area, Common photoacoustic gas detection systems in laboratories are not suitable for fire alarm due to their poor real-time performance and high wavelength qualification for the optical setup. Besides, they are too complex and expensive. Researchers of this project developed the photoacoustic gas detection technique and designed an unusual photoacoustic gas detection system [75-76]. The new system removes the limitations of common detection systems by a different system design in which an enclosed photoacoustic cell filled with $\mathrm{CO}$ is used to achieve CO selection instead of optical filters or laser infrared source.

Some other signals can also be used to detect early-stage fires. Researchers measured the particle size distributions of several types of fire smoke by the near-forward scattering light of laser sheet based on Mie scattering theory [77]. Results showed that there exists a critical particle size which can exclude the disturbance of dust [78]. Another interesting result is that there exits self-preserving size distribution of the smoke soot agglomeration of flame combustion in the flame region and above the flame region [79]. Based on these, one multi-signal sensing \& processing system for detecting early-stage fires has been established at SKLFS [80].

\section{Water Mist Fire Suppression System}

Water mist fire suppression technology has already received considerable attention in China. Researchers developed one non-intrusive pattern method to characterize a water mist by the droplet size and velocity distribution, the water mist atomization angle and the breakup length. This PIVS (particle image velocimetry and sizing) method is mainly based on the manipulation of digital particle images [81-82]. 
Researchers also extensively investigated the interaction of fine water mists with many kinds of fires [83], such as solid pool fires [84], diffusion flame of liquid fuel [85-87]. In order to enhance fire suppression effectiveness, some additives are added into water mist. Researcher [88] found that sodium chloride additive has a significant impact on fire suppression effectiveness, and a W shape relationship exists between the fire suppression time and the mass concentration of sodium chloride. The results implied that there may be an optimal mass concentration for the fire suppression effectiveness.

\section{CONCLUDING REMARKS AND PROSPECT}

As planed, the project will be implemented by the end of 2006. As can be seen, the progress of the project covers both the fire dynamical theory and the principle of advanced fire protection technologies. For the former, many complex fire phenomena have been successfully described by reasonable experiments or simulation means, and deep insights into the behaviors and as well the relevant physical or chemical mechanisms for the processes of decomposition, ignition, fire propagation, and even special fire stages such as backdraft, flashover and firewhirl have been achieved. For the latter, some remarkable ideas and means of developing advanced technologies of fire retardant, fire detection, and fire suppression by combining different technique principles in different fields have witnessed successes. In addition, the fire risk assessment method developed in this project has been successfully applied in practical engineering, indicating a good connection between the fundamental research and the engineering practice motivated by this project.

In China, the increasing fire disasters in recent years are calling nationwide and even world-wide attention, and fire would continue to be in the foreseeable future one of the major disasters threatening the life and industrial safety. In the new China National Midlong Term Planning of Science and Technology (2006-2020), Public Security has been recognized as one of the key research fields, in which fire safety is of particularly importance since it is closely related to daily life security. Under this situation, it is expected that more and more fire fundamental research projects will be promoted and supported by the national research plans such as National Key Technologies R\&D Program, 973 Program, National High-tech R\&D Program (863 Program), and so on.

As can be anticipated, the economy growing in China will continue to induce more and more complex fire types. There still remains high challenge in revealing the mechanisms and behaviors of fire phenomena and as well developing advance fire protection technologies. It can be expected that the future fire fundamental research in China will become more closely correlated with practical requirements of fire protection. In fact, the progress of the present project benefits greatly from the multidisciplinary collaboration in both fields of fundamental research and practical technological research. The fire scenarios that commonly occur in China should be especially addressed, and the knowledge innovation based on the combination of deep understanding of fire deterministic behaviors and its statistical characteristics will be the major direction for China fundamental fire research.

\section{ACKNOWLEDGEMENTS}

This work was sponsored by the China NKBRSF project (No. 2001CB409600), National Natural Science Foundation of China under Grants 50346038 and 50323005, the Anhui Excellent Youth Scientist Foundation (2004-2006), USTC Youth Fund, the National Key Technologies R\&D Programme (2001BA510B09-03). 


\section{REFERENCES}

1. Liu, N.A., Fan, W.C., Dobashi, R., and Huang, L.S., "Kinetic Modeling of Thermal Decomposition of Natural Cellulosic Materials in Air Atmosphere," Journal of Analytical and Applied Pyrolysis, 63, pp. 303-325, (2002).

2. $\quad$ Liu, N.A., Fan, W.C., Dobashi, R., and Lin, Q.Z., "New Mass Loss Kinetic Model for Thermal Decomposition of Biomass," Chinese Science Bulletin, 46, pp. 1398-1402, (2001).

3. Huang, H.C., Chang, C.Y., Chen, Y.H., Shie, J.L., Lin, J.P., and Wu, C.H., "Resources Recovery of Waste Rayon by Pyrolysis: Kinetics Study," Journal of the Chinese Institute of Chemical Engineers, 35, pp. 623-632, (2004).

4. Ledakowicz, S. and Stolarek, P., "Kinetics of Biomass Thermal Decomposition,” Chemical Papers-Chemicke Zvesti, 56, pp. 378-381, (2002).

5. Meszaros, E., Varhegyi, G., and Jakab, E., "Thermogravimetric and Reaction Kinetic Analysis of Biomass Samples from an Energy Plantation,” Energy \& Fuels, 18, pp. 497-507, (2004).

6. Shi, H.Y., Fang, M.X., and Wang, S.R., "Kinetic Study on the Pyrolysis of Some Wood Used in Building and Decorating (in Chinese)," Fire Safety Science, 11, pp. 211-216, (2002).

7. Shi, H.Y., Fang, M.X., Wang, S.R., Yu, C.J., Luo, Z.Y., and Cen, K.F., "Kinetic Study on the Pyrolysis of Combustible Textile," Fire Science and Technology (in Chinese), 22, pp. 436-440, (2003).

8. Shi, H.Y., "Kinetic Study of Fire Combustible Pyrolysis (in Chinese)," Master Dissertation, Zhejing University, (2004).

9. Punnaruttanakun, P., Meeyoo, V., Kalambaheti, C., Rangsunvigit, P., Rirksomboon, T., and Kitiyanan, B., "Pyrolysis of API Separator Sludge," Journal of Analytical and Applied Pyrolysis, 68-9, pp. 547-560, (2003).

10. Yu, C.J., Zhou, J.S., Liao, Y.F., Luo, Z.Y., and Cen, K.F., "Numerical Simulation of Secondary Reactions Inside Hardwood Particle during Pyrolysis. I. Construction of Single Particle Pyrolysis Model," Journal of Fuel Chemistry and Technology (in Chinese), 30, pp. 336-341, (2002).

11. Yu, C.J., Zhou, J.S., Liao, Y.F., Luo, Z.Y., and Cen, K.F., "Numerical Simulation of Secondary Reactions inside Hardwood Particle during Pyrolysis. II. Numerical Simulation Results,” Journal of Fuel Chemistry and Technology (in Chinese), 30, pp. 413-417, (2002).

12. Liu, N.A., Chen, H.X., Shu, L.F., Zong, R.W., Yao, B., and Statheropoulos, M., "Gaussian Smoothing Strategy of Thermogravimetric Data of Biomass Materials in an Air Atmosphere," Industrial \& Engineering Chemistry Research, 43, pp. 4087-4096, (2004).

13. Chen, H.X., Liu, N.A., Shu, L.F., and Zong, R.W., "Smoothing and Differentiation of Thermogravimetric Data of Biomass Materials," Journal of Thermal Analysis and Calorimetry, 78, pp. 1029-1041, (2004).

14. Yang, L.Z., Chen, X.J., Zhou, X.D., and Fan, W.C., "The Pyrolysis and Ignition of Charring Materials under an External Heat Flux," Combustion and Flame, 133, pp. 407-413, (2003). 
15. Zhang, J.Y., Yang, L.Z., Guo, Z.F., and Deng, Z.H., "Experimental Study on the Factors Concerning the Ignition Time and Mass Loss Rate of Timber,” Journal of Fire Sciences, 21, pp. 29-39, (2003).

16. Guo, Z.F., Yang, L.Z., Deng, Z.H., Zhang, J.Y., and Fan, W.C., "Experimental Study on Charring of Wood under Simulated Fire," Journal Of Combustion Science and Technology (in Chinese), 9, pp. 16-20, (2003).

17. Yang, L.Z., Guo, Z.F., Zhang, J.Y., Chen, X.J., and Deng, Z.H., "Experimental Study on Scale Effect on Mass Loss Rate of Some Woods," Journal of Fire Sciences, 20, pp. 23-35, (2002).

18. Ji, J.W., "Study on Criterion for Wood Ignition at Variable Heat Flux and Its Application (in Chinese)," PhD Dissertation, USTC, (2003).

19. Ji, J.W., Song H., Yang, L.Z., and Fan, W.C., "The Ignition and the Forecast Model of Wood Blocks in a Bench-scale Flashover Apparatus," Engineering Science (in Chinese), 5, pp. 62-66, (2003).

20. Ji, J.W., Yang, L.Z., and Fan, W.C., "Experimental Study on Effects of Burning Behaviours of Materials Caused by External Heat Radiation,” Journal of Combustion Science and Technology (in Chinese), 9, pp. 139-143, (2003).

21. Ji, J.W., Cheng Y.P., Yang, L.Z., and Fan, W.C., "Numerical Simulation of Fire Development in a Single Compartment Based on Cone Calorimeter Experiments," Progress In Natural Science (in Chinese), 12, pp. 368-372, (2002).

22. Song, H., Yang, L.Z., Fan, W.C., and Weng, W.G., "The Effect of Fire Source with Sand on the Temperature of Compartmental Fires," Engineering Science (in Chinese), 4, pp. 59-62, (2002).

23. Zhang, J., Wang, X.Y., Zhang, F., and Horrocks, A.R., "Estimation of Heat Release Rate for Polymer-filler Composites by Cone Calorimetry," Polymer Testing, 23, pp. 225-230, (2004).

24. Liu, X. and Zhang J., "Effects of Essential Parameters of Cone Calorimeter on Heat Release Rate Measurement for Polymeric Materials," Polymer Materials Science and Engineering, 19, pp. 27-30, (2003).

25. Weng, W.G. and Fan, W.C., "Critical Condition of Backdraft in Compartment Fires: A Reduced-scale Experimental Study," Journal of Loss Prevention in the Process Industries, 16, pp. 19-26, (2003).

26. Weng, W.G., Fan, W.C., Yang, L.Z., Song, H., Deng, Z.H., Qin, J., and Liao, G.X., "Experimental Study of Back-draft in a Compartment with Openings of Different Geometries," Combustion and Flame, 132, pp. 709-714, (2003).

27. Weng, W.G. and Fan, W.C., "Experimental Study on the Mitigation of Backdraft in Compartment Fires with Water Mist,” Journal of Fire Sciences, 20, pp. 259-278, (2002).

28. Weng, W.G. and Fan, W.C., "Mitigation of Backdraft with Water Mist: A Reduced-scale Experimental Study,” Process Safety Progress, 22, pp. 163-168, (2003).

29. Weng, W.G. and Fan, W.C., "Nonlinear Analysis of the Backdraft Phenomenon in Room Fires,” Fire Safety Journal, 39, pp. 447-464, (2004). 
30. Weng, W.G., Fan, W.C., Wang, Q.A., and Yang, L.Z., “A Model of Backdraft Phenomenon in Building Fires," Progress In Natural Science (in Chinese), 12, pp. 131-135, (2002).

31. Weng, W.G. and Fan, W.C., "Catastrophe Analysis of Flashover in Building Fires,” Fire Safety Science, 12, pp. 51-57, (2003).

32. Lu, P., Li, P.D., Fan, W.C., and Liao, G.X., "Experimental Research on the Process of Fire Flashover of Confined Compartment (in Chinese)," Fire Safety Science, 12, pp. 213-217, (2003).

33. Mid-term Report of 973 Project (2001CB409602), (2004).

34. Kohyu Satoh and Yang, K.T., "Measurements of Fire Whirls from a Single Flame in a Vertical Square Channel with Symmetrical Corner Gaps," Fundamentals of Heat Transfer in Flames, 1999 ASME HTD, 364-4, pp. 167173.

35. Liu, N. A., 2005 Report of 973 Project (2001CB409602), (2005).

36. Chen, X.J., Yang, L.Z., Deng, Z.X., and Fan, W.C., "A Multi-layer Zone Model for Predicting Temperature Distribution in a Fire Room," Progress In Natural Science (in Chinese), 14, pp. 536-540, (2004).

37. Yang, R., Jiang, Y., Ji, J., Fan, W. C., "Field-zone Building Fire Numerical Model Based on Large Eddy Modeling and its Application," Progress in Natural Science (in Chinese), 6, pp. 637-641, (2003).

38. Fu, S. and C.K. Chow, Mid-term Report of 973 Project (2001CB409604), (2004).

39. Qin, T.X., Guo, Y.C., Chan, C.K., Lau, K.S., and Lin, W.Y., "Numerical Simulation of Fire-induced Flow through a Stairwell," Building and Environment, 40, pp. 183-194, (2005).

40. Hu, L.H., Huo, R., Yao, B. and Wang, H.B., "Preliminary Study on Engineering Method to Predict Smoke Movement in Very Long-narrow Spaces with Two Closing Ends (in Chinese)," Fire Safety Science, 12, pp. 36-39, (2003).

41. Hu, L.H., Li, Y.Z., Huo, R., and Wang, H.B., "Smoke Filling Simulation in a Boarding-arrival Passage of an Airport Terminal using Multicell Concept," Journal of Fire Sciences, 23, pp. 31-53, (2005).

42. Zhong, Z.R., Zhou, J.J., Zou, Y.H., and Zhu, J.P., "Study on the Model of Wildland Fire Spread (in Chinese),” Fire Safety Science, 10, pp. 83-87, (2001).

43. Tian, X.R., Shu, L.F., and Wang, M., "Direct Carbon Emissions from Chinese Forest Fires, 1991-2000 (in Chinese),” Fire Safety Science, 12, pp. 6-10, (2003).

44. Wang, M., Shu, L.F., Tian, X.R., and Shi, J., "Spatial Fluctuation of Forest Fires and Their Response to Global Change (1) (in Chinese)," Fire Safety Science, 12, pp. 165-170, (2003).

45. Wang, M., Shu, L.F., Tian, X.R., and Shi, J., "Spatial Fluctuation of Forest Fires and Their Response to Global Change (2) (in Chinese),” Fire Safety Science, 12, pp. 171-176, (2003).

46. Song, W.G., Fan, W.C., Wang, B.H., and Zhou, J.J., "Self-organized Criticality of Forest Fire in China,” Ecological Modeling, 145, pp. 61-68, (2001). 
47. Song, W.G., Fan, W.C., and Wang, B.H., "Self-organized Criticality of Forest Fires in China,” Chinese Science Bulletin 46, pp. 1134-1137, (2001).

48. Song, W.G., Fan, W.C., and Wang, B.H., "Influences of Finite-size Effects on the Self-organized Criticality of Forest-fire Model,” Chinese Science Bulletin, 47, pp. 177-180, (2002).

49. Song, W.G., Zhang, H.P., Chen, T., and Fan, W.C., "Power-law Distribution of City Fires,” Fire Safety Journal, 38, pp. 453-465, (2003).

50. Chen, T., "Model and Application Study during Fire Evacuation (in Chinese)," PhD Dissertation, USTC, (2004).

51. Lu, S.X. and Qian, J.M., Mid-term Report of 973 Project (2001CB409606), (2004).

52. Song, W.G., Yu, Y.F., and Chen, T., "Influences of Exit Conditions on Pedestrian Evacuation (in Chinese)," Fire Safety Science, 12, pp. 100-104, (2003).

53. Chen, T., Song, W.G., Fan, W.C. and Lu, S.X., "Study of Evacuation Jamming Transition in Crossing Exit,” Engineering Science (in Chinese), 6, pp. 57-60, (2004).

54. Sun, J.H., Sun, Z.H., Lu, S.X., and Fan, W.C., “Collapse Probability of Building Caused by Fire,” Engineering Science (in Chinese), 5, pp. 51-55, (2003).

55. Sun, Z.H., Yao, B., and Sun, J.H., “Application of Design Fire and Fire Hazard Degree Analysis in Hazard Identification of Performance based Fire Protection Design (in Chinese),” Fire Safety Science, 13, pp. 106-110, (2004).

56. Li, B.G., Hu, Y., Zhang, R., Chen, Z.Y., and Fan, W.C., "Preparation of the Poly (vinyl alcohol)/layered Double Hydroxide Nanocomposite,” Materials Research Bulletin, 38, pp. 1567-1572, (2003).

57. Hao, L.Y., Zhu, C.L., Mo, X., Jiang, W.Q., Hu, Y., Zhu, Y.R., and Chen, Z.Y. "Preparation and Characterization of $\mathrm{Mg}(\mathrm{OH})(2)$ Nanorods by Liquid-solid Arc Discharge Technique,” Inorganic Chemistry Communications, 6, pp. 229-232, (2003).

58. Tang, Y., Hu, Y., Wang, J.Z., Zong, R.W., Gui, Z., Chen, Z.Y., Zhuang, Y.L., and Fan, W.C., "Influence of Organophilic Clay and Preparation Methods on EVA/montmorillonite Nanocomposites,” Journal of Applied Polymer Science, 91, pp. 2416-2421, (2004).

59. Tang, Y., Hu, Y., Wang, S.F., Gui, Z., Chen, Z.Y., and Fan, W.C., "Novel Preparation of Poly(propylene)-layered Silicate Nanocomposites,” Journal of Applied Polymer Science, 89, pp. 2586-2588, (2003).

60. Hu, Y., Song, L., Xu, J., Yang, L., Chen, Z., and Fan, W.C., "Synthesis of Polyurethane/clay Intercalated Nanocomposites,” Colloid and Polymer Science, 279, pp. 819-822, (2001).

61. Hu, Y., Wang, S.F., Ling, Z.H., Zhuang, Y.L., Chen, Z.Y., and Fan, W.C., "Preparation and Combustion Properties of Flame Retardant Nylon 6/montmorillonite Nanocomposite,” Macromolecular Materials and Engineering, 288, pp. 272-276, (2003). 
62. Hu, Y., Xu, J.Y., Wang, S.F., Wang, Q.A. and Chen, Z.Y., "Preparation and Characterization of Polymer/graphite Oxide Nanocomposites," Rare Metal Materials and Engineering, 30, pp. 592-595, (2001).

63. Li, B.G., Hu, Y., Liu, J. Chen, Z.Y., and Fan, W.C., "Preparation of Poly (methyl methacrylate)/LDH Nanocomposite by Exfoliation-adsorption Process," Colloid and Polymer Science, 281, pp. 998-1001, (2003).

64. Song, L., Hu, Y., Wang, S.F., Chen, Z.Y., and Fan, W.C., "Study on the Solvothermal Preparation of Polyethylene/organophilic Montmorillonite Nanocomposites," Journal of Materials Chemistry, 12, pp. 3152-3155, (2002).

65. Tang, Y., Hu, Y., Li, B.G., Liu, L., Wang, Z.Z., Chen, Z.Y., and Fan, W.C., "Polypropylene/montmorillonite Nanocomposites and Intumescent, Flameretardant Montmorillonite Synergism in Polypropylene Nanocomposites," Journal of Polymer Science Part A-Polymer Chemistry, 42, pp. 6163-6173, (2004).

66. Tang, Y., Hu, Y., Zhang, R., Wang, Z.Z., Gui, Z., Chen, Z.Y., and Fan, W.C., "Investigation into Poly(propylene)/montmorillonite/calcium Carbonate Nanocomposites," Macromolecular Materials and Engineering, 289, pp. 191197, (2004).

67. Wang, S.F., Hu, Y., Lin, Z.H., Gui, Z., Wang, Z.Z., Chen, Z.Y. and Fan, W.C., "Flammability and Thermal Stability Studies of ABS/Montmorillonite Nanocomposite," Polymer International, 52, pp. 1045-1049, (2003).

68. Wang, S.F., Hu, Y., Qu, Z.K., Wang, Z.Z., Chen, Z.Y. and Fan, W.C., "Preparation and Flammability Properties of Polyethylene/clay Nanocomposites by Melt Intercalation Method from Na+ montmorillonite,” Materials Letters, 57, pp. 2675-2678, (2003).

69. Wang, S.F., Hu, Y., Song, L., Wang, Z.Z., Chen, Z.Y. and Fan, W.C., "Preparation and Thermal Properties of ABS/montmorillonite Nanocomposite," Polymer Degradation and Stability, 77, pp. 423-426, (2002).

70. Wang, S.F., Hu, Y., Wang, Z.Z., Tang, Y., Chen, Z.Y. and Fan, W.C., "Synthesis and Characterization of Polycarbonate/ABS/montmorillonite Nanocomposites,” Polymer Degradation and Stability, 80, pp. 157-161, (2003).

71. Wang, S.F., Hu, Y., Zong, R.W., Tang, Y., Chen, Z.Y. and Fan, W.C., "Preparation and Characterization of Flame Retardant ABS/montmorillonite Nanocomposite," Applied Clay Science, 25, pp. 49-55, (2004).

72. Xu, J.Y., Hu, Y., Song, L., Wang, Q.G., Fan, W.C., and Chen, Z.Y., "Preparation and Characterization of Poly (vinyl alcohol)/graphite Oxide Nanocomposite," Carbon, 40, pp. 450-451, (2002).

73. Chen, W., and Qu, B.J., "Structural Characteristics and Thermal Properties of PE-g-MA/MgAl-LDH Exfoliation Nanocomposites Synthesized by Solution Intercalation," Chemistry of Materials, 15, pp. 3208-3213, (2003).

74. Chen, W., Feng, L., and Qu, B.J., "Preparation of Nanocomposites by Exfoliation of ZnAl Layered Double Hydroxides in Nonpolar LLDPE Solution," Chemistry of Materials, 16, pp. 368-370, (2004). 
75. Chen, T., Su, G.F., Shu, X.M., Yuan, H.Y., and Fan, W.C., "Design of a Photoacoustic Gas Detection System for Fire Warning,” Engineering Science (in Chinese), 6, pp. 60-64, (2004).

76. Chen, T., "Photoacoustic Multi-sensor Fire Detection for Gas and Smoke Particles," (in Chinese) PhD Dissertation, USTC, (2004).

77. Xu, Q., and Yuan, H.Y., "Measurement of Smoke Particle Size Distribution by the Near-forward Scattering Light of Laser Sheet (in Chinese)," Fire Safety Science, 12, pp. 95-99, (2003).

78. Xie, Q.Y., Yuan, H.Y., and Jiang, Y., "The Base Smoke Density of Smoke Fire Detector Created by the Suspended Particulate PM10 in Atmosphere," Engineering Science (in Chinese), 5, pp. 84-87, (2003).

79. Fang, J., Shu, X.M., Yuan, H.Y., and Zheng, X., "Self-preserving Size Distribution of Fire Soot Fractal Coagulation in Flaming Combustion,” Journal of Fire Sciences, 22, pp. 53-68, (2004).

80. Li, J. and Yuan, H.Y., Mid-term Report of 973 Project (2001CB409608), (2004).

81. Wang, X.S., Wu, X.P., Liao, G.X., Wei, Y.X., and Qin, J., “Characterization of a Water Mist Based on Digital Particle Images,” Experiments In Fluids, 33, pp. 587-593, (2002).

82. Wang, X.S., Wu, X.P., and Liao, G.X., "A Method of Extending DPIV and its Application in Spray Droplet Size Measurements,” Chinese Science Bulletin, 47, pp. 1045-1049, (2002).

83. Liu, J.H., Liao, G.X., Li, P.D., Fan, W.C. and Lu, Q., "Progress in Research and Application of Water Mist Fire Suppression Technology," Chinese Science Bulletin, 48, pp. 718-725, (2003).

84. Liu, J.H., Liao, G.X., Li, P.D., Qin, J. and Lu, X.Y., "Experimental Study on the Interaction of Fine Water Mist with Solid Pool Fires,” Science In China Series E-Engineering \& Materials Science, 46, pp. 218-224, (2003).

85. Liu, J.H., Liao, G.X., Li, P.D., and Yao, B., "Preliminary Study on Interaction of Water Mist with Diffusion Flame of Liquid Fuels," Progress in Natural Science (in Chinese), 13, pp. 237-240, (2003).

86. Wang, X.S., Liao, G.X., Qin, J., and Yao, B., "Interaction of Water Mist with Flame by the Infrared Field Diagnostic Method," Journal of Infrared and Millimeter Waves, (in Chinese) 18, pp. 311-316, (1999).

87. Liu, J.H., Liao, G.X., Fan, W.C., Yao, B. and Lu, X.Y., "Study of Liquid Pool Fire Suppression with Water Mists by Cone Calorimeter," Journal of Fire Sciences, 20, pp. 465-477, (2002).

88. Cong, B.H., Mao, T., and Liao, G.X., "Experimental Investigation on Fire Suppression Effectiveness for Pool Fires by Water Mist Containing Sodium Chloride Additive,” Journal of Thermal Science and Technology (in Chinese), 3, pp. 65-70, (2004). 